\title{
The Influence of Induction Sintering on Microstructure and Deformation Behavior of Ti-5Al-5Mo-5V-3Cr Alloy
}

\author{
KRYSTIAN ZYGUŁA, MAREK WOJTASZEK, TOMASZ ŚLEBODA, \\ SEBASTIAN LECH, OLEKSANDR LYPCHANSKYI, GRZEGORZ KORPAŁA, \\ and ULRICH PRAHL
}

\begin{abstract}
The influence of the induction sintering process at different temperatures on the behavior of the powder metallurgy Ti-5Al-5Mo-5V-3Cr alloy was investigated. Material for the research was produced by elemental powder blending, followed by the uniaxial cold compacting process. Powder compacts were induction heated and sintered within the temperature range of $1000{ }^{\circ} \mathrm{C}$ to $1300{ }^{\circ} \mathrm{C}$. The influences of process parameters on the material behavior during sintering and its properties were studied. The microstructure examination was performed with particular attention to the pore size and distribution as well as the homogenization of the microstructure. The sintering temperature of $1200^{\circ} \mathrm{C}$ proved to be critical for the dissolution of most alloying powder particles. Hot compression tests were performed to determine the formability of the obtained material. Significant differences in flow stress behavior between samples sintered at temperatures below and above $1200{ }^{\circ} \mathrm{C}$ were observed. The mechanical properties of the material before and after deformation were compared. The evolution of the microstructure of sintered Ti-5Al-5Mo-5V-3Cr alloy after hot deformation was analyzed with an emphasis on its influence on the material properties. Based on the conducted research, it was found that the adequate homogenization of the chemical composition and microstructure was achieved at the temperature of $1250^{\circ} \mathrm{C}$, and a further increase did not reflect in a significant improvement.
\end{abstract}

https://doi.org/10.1007/s11661-021-06179-8

(C) The Author(s) 2021

\section{INTRODUCTION}

THE unique combination of high mechanical properties, corrosion resistance, and low density of $\beta$ titanium alloys has made them widely applied as critical components in the aerospace industry and high-performance racing cars. ${ }^{[1,2]}$ Relatively low Young's modulus combined with excellent biocompatibility made vanadium-free titanium alloys popular in medical applications such as dental implants and bone replacements. Due to the high strength (up to $1500 \mathrm{MPa}$ ) and high fatigue properties (about $700 \mathrm{MPa}$ ), the Ti-5Al-5Mo-5V-3Cr (Ti-5553) alloy found its application in

KRYSTIAN ZYGUŁA, MAREK WOJTASZEK, TOMASZ ŚLEBODA, SEBASTIAN LECH, and OLEKSANDR LYPCHANSKYI are with the Faculty of Metals Engineering and Industrial Computer Science, AGH University of Science and Technology, Al. A. Mickiewicza 30, 30-059 Krakow, Poland. Contact e-mail: kzygula@agh.edu.pl GRZEGORZ KORPAŁA, and ULRICH PRAHL are with the Institut für Metallformung, TU Bergakademie Freiberg, 4 Bernhard-von-Cotta-Straße, 09596 Freiberg, Germany.

Manuscript submitted August 12, 2020; accepted January 31, 2021.

Article published online March 4, 2021 airplane landing gear assemblies. ${ }^{[1,3]}$ Currently, Ti-5553 alloy is gradually replacing $\mathrm{Ti}-10 \mathrm{~V}-2 \mathrm{Fe}-3 \mathrm{Al}$ alloy because of the wider processing window and better hardenability, which brings weight-savings benefits. Nevertheless, the production costs of titanium structural parts are still relatively high. ${ }^{[2,4]}$ The application of powder metallurgy methods in the manufacturing of titanium alloys has become more popular because of the possible reduction of production costs by manufacturing near-net shape products and hence reduce machining. The most promising approach is thermomechanical consolidation of a mixture of elemental powders which involves the use of a relatively inexpensive blend of elemental powders followed by a cold compaction process and high-temperature sintering. ${ }^{[5-7]}$ Currently, researchers have focused on studying the behavior of master alloy powders during material production using powder metallurgy methods. This approach ensures high homogenization of the chemical composition but may increase the overall costs. Research on the effect of pure elemental powders focuses only on the use of pure Ti. There is a lack of comprehensive knowledge about the behavior of a mixture of pure elemental powders during cold pressing and sintering at high temperature 
as well as their influence on the homogenization of the chemical composition and microstructure.

Optimization of sintering parameters is a crucial step to achieve high relative density and good mechanical properties. For the alloys with complex chemical compositions, the diffusion level of alloying elements determines the chemical and microstructural homogenization as well as the volume fraction of phases and grain morphology. Usually, the conventional sintering process is carried out in a sintering furnace and may take up to several hours, which leads to excellent chemical homogenization, but also extensive grain growth. To protect material from this effect and reduce the sintering time, other techniques such as electric current-assisted sintering (ECAS) ${ }^{[8]}$ spark plasma sintering (SPS) ${ }^{\left[{ }^{[1}\right.}$ microwave sintering ${ }^{[0]}$ and induction sintering ${ }^{[11]}$ were developed. Various thermally activated mechanisms are responsible for material transfer during sintering, causing a density increase. Phenomena such as volume diffusion, grain boundary diffusion, surface diffusion, and viscous or plastic flow occur during the densification process. ${ }^{[12]}$ The mechanisms mentioned above can be activated during the sintering process either simultaneously or sequentially. Generally, the early stage of sintering starts with neck formation in the contact area between two neighboring particles. Then, the filling of the vacancy due to the lattice diffusion of atoms from the grain boundary to the neck area occurs. ${ }^{[13,14]}$ In general, diffusion processes are complex and depend on various factors, such as particle shape, size, distribution and microstructure as well as process parameters, which are temperature, atmosphere and time.

Controlling the microstructure reflects in the mechanical properties of titanium alloys and leads to the improvement of the performance of the material during application. Basic methods used for microstructure modifications are deformation processes, especially severe plastic deformation (SPD) techniques such as equal channel angular pressing (ECAP), hot forging, rolling and extrusion, or high-pressure torsion (HPT). ${ }^{[15-19]}$ Due to the properly designed hot deformation process, significant grain refinement can be obtained. Determination of favorable deformation parameters can be done by constructing flow curves under various conditions. Titanium alloys are relatively sensitive to changes in deformation conditions. ${ }^{[20]}$ Therefore, it is important to provide a rheological description of the new and unconventional titanium-based material. A typical microstructure of titanium alloy fabricated by powder metallurgy is mainly composed of $\alpha$ grains with a bimodal size distribution, where fine plate-like grains are surrounded by large, lamellar grains located at the primary beta grain boundaries. ${ }^{[21]}$ Breakdown of the initial microstructure during hot deformation results in significant $\alpha$ grain fragmentation if deformation takes place below the $\beta$-transus temperature or dynamic recrystallization (DRX) and formation of the fine equiaxed structure if deformation takes place above the $\beta$-transus temperature. ${ }^{[22]}$ Each type of mentioned microstructure has its advantages and disadvantages, which are manifested in fluctuations of the mechanical properties. For example, the lamellar microstructure is characterized by good fracture toughness, similar to the fine-grained $\alpha$ microstructure, which also has good strength properties, while the equiaxed $\beta$ microstructure has better ductility but poor fracture toughness. Additionally, when grains are coarse the strength decreases. ${ }^{[23]}$

This study investigates the sintering behavior of the Ti-5553 alloy obtained by the blended elemental powder metallurgy (BEPM) method. The powder mixture was cold-compacted and induction sintered at different temperatures. The influence of the sintering temperature on the shrinkage, relative density as well as pore size and distribution was investigated. A detailed microstructure examination was performed with particular attention to the dissolution of powder particles. Moreover, the formability of the obtained material was tested, and the evolution of the microstructure during hot compression and its influence on the material properties were described.

\section{MATERIALS AND METHODS}

The elemental powders used in this research were titanium, aluminum, molybdenum, vanadium and chromium. Commercially pure Ti powder (with particle size $<150 \mu \mathrm{m}$ and purity $\geq 99.5 \mathrm{pct}$ ) and $\mathrm{V}$ powder (with particle size $<150 \mu \mathrm{m}$ and purity $\geq 99.9$ pct) were produced using the hydrogenation-dehydrogenation $(\mathrm{HDH})$ process. Atomized Al powder had a size up to $35 \mu \mathrm{m}$ and a purity of 99.8 pct. Molybdenum and chromium powders had a size up to 35 and $65, \mu \mathrm{m}$ respectively, and a purity of 99.9 and 99.2 pct, respectively. Powders were blended for 5400 second with a rotational speed of $55 \mathrm{rpm}$. The tungsten carbide balls were added to the mill container to intensify the mixing process by crushing particles and inserting softer particles to the surface of the other, harder particles. As a result, the powder mixture with a chemical composition corresponding to the Ti-5553 alloy was obtained (Table I). To analyze the morphology of the elemental powders, the Hitachi HM-3000 (Hitachi, Ltd., Tokyo, Japan) scanning microscope was used.

The prepared mixture was compacted at room temperature under the pressure of $100 \mathrm{MPa}$ in a cylindrical die with a diameter of $10 \mathrm{~mm}$. Additionally, during compaction, lubrication was used in the form of lithium-based aerosol grease with PTFE, which significantly influenced the efficiency of the process. The density of samples was measured by the Archimedes method, where the temperature of water was about 20 ${ }^{\circ} \mathrm{C}$. Samples were waxed before measurement to prevent soaking. The average relative density of cold-compacted samples was: $82.7 \pm 1.7$ pct (in reference to the theoretical bulk density of Ti-5553 alloy, which is 4.68 $\left.\mathrm{g} / \mathrm{cm}^{3[24]}\right)$. Then, compacts were sintered under vacuum using the Bähr MDS 830 Multi-Directional Deformation Simulator (BÄHR Thermoanalyse GmbH, Hüllhorst, Germany). Induction heating was applied, with a heating rate of $100 \mathrm{~K} / \mathrm{s}$. The cooling rate was $25 \mathrm{~K} / \mathrm{s}$. The temperature was controlled by a K-type thermocouple, which was welded on the side of the sample. 
Table I. Nominal Chemical Composition of Ti-5553 Alloy ${ }^{[24]}$

\begin{tabular}{cccccccccc}
\hline & Al & Mo & V & Cr & O & H & N & C & Ti \\
\hline Nominal Composition, Pct & 4.4 to 5.7 & 4.0 to 5.5 & 4.0 to 5.5 & 2.5 to 3.5 & $<0.18$ & $<0.015$ & $<0.05$ & $<0.1$ & bal. \\
\hline
\end{tabular}

Diameter changes during sintering were measured by laser detectors. Height change of the sample during sintering was neglected because of the application of ceramic plates that block the expansion in this direction. The tests were carried out at the following temperatures: $1000{ }^{\circ} \mathrm{C}, 1100{ }^{\circ} \mathrm{C}, 1200{ }^{\circ} \mathrm{C}, 1250{ }^{\circ} \mathrm{C}$ and $1300^{\circ} \mathrm{C}$.

Sintered samples were prepared for microstructural observations through grinding and polishing, followed by etching using Kroll's reagent consisting of 2 pct HF, 2 pct $\mathrm{HNO}_{3}$ and 94 pet $\mathrm{H}_{2} \mathrm{O}$. The microstructure analysis was performed using a Keyence VHX-S660E (Keyence Corp., Osaka, Japan) digital microscope and Leica DM4000M (Leica Microsystems GmbH, Wetzlar, Germany) light microscope. The average porosity was determined from the micrographs, and pores size was measured using Leica Application Suite 4.8 software. For a detailed analysis of the alloying powder particle dissolution and homogenization, a Merlin Gemini II (Carl Zeiss AG, Oberkochen, Niemcy) scanning electron microscope equipped with the electron dispersive X-ray spectrometer (EDS) was used.

To develop the flow behavior of sintered material, hot deformation tests were performed using the WUMSI Servo-Hydraulic Hot Deformation Simulator (Warmumformsimulator). Samples were heated up to the temperature of $1000{ }^{\circ} \mathrm{C}$ and compressed with a strain rate of $1 \mathrm{~s}^{-1}$ and then air-cooled. The average hardness of sintered as well as deformed material was determined by the Vickers method with a load of $9.8 \mathrm{kN}$ using a Struers Duramin-40 (Struers ApS, Ballerup, Denmark) hardness tester.

\section{RESULTS}

\section{A. Initial Material}

The morphology of elemental powders used in this study, as well as the prepared mixture, is shown in Figure 1. Titanium, molybdenum, vanadium and chromium powders had irregularly shaped particles with a rough surface. The application of irregular powders instead of spherical ones leads to an increase in density and reduction of pore size after compaction. ${ }^{[25]}$ On the other hand, gas atomized aluminum particles are smooth and shaped like droplets. All elemental powder particles had satellites (particles, with size not exceeding a few micrometers) welded to their surface. The presence of satellites may have a negative impact on some powder applications, but this mostly concerns the flow of particles through the nozzle in $3 \mathrm{D}$ printing processes. $^{[26,27]}$ As a result of the blending process, the uniform distribution of elemental powders was achieved. Larger particles were broken up and softer particles, such as aluminum powder particles, were inserted on the surface of other ingredients of the mixture, which led to better chemical homogenization.

\section{B. Densification Studies}

Figure 2(a) shows the relative density of the samples sintered at each condition and an increment of density after the sintering process. Irrespective of the temperature, the sintering process caused an increase of the relative density compared to the density after the cold compacting process. The relative density increased with an increase in the sintering temperature up to $1250^{\circ} \mathrm{C}$. A further increase of the temperature had no significant influence on the density of the sample, taking into consideration that after the cold compacting process the density was already relatively high and the differences between samples were slight. The density increment after the sintering process in relation to the temperature is presented as gray bars in Figure 2(a). It can be observed that increasing temperature results in more efficient densification of the powder compact.

Densification parameter $\psi$ indicates the ability of the cold-compacted sample to densify during the sintering process. Equation [1] was used to calculate the $\psi$ parameter:

$$
\psi=\frac{\rho_{s}-\rho_{g}}{\rho_{t}-\rho_{g}}
$$

where $\rho_{\mathrm{s}}$ is the density of the compact after sintering, $\rho_{\mathrm{g}}$ is the density of the compact after the cold compacting process, and $\rho_{\mathrm{t}}$ is the theoretical density of the solid material. ${ }^{[28]}$ Similarly to the relative density values, the densification parameter increases with increasing sintering temperature up to $1250{ }^{\circ} \mathrm{C}$, and it is about 0.07 higher compared to that obtained by the sintering at $1000{ }^{\circ} \mathrm{C}(0.24$ and 0.17 , respectively).

\section{Sintering Curves}

The sintering curves obtained during sintering at the applied temperatures are shown in Figure 3(a). In general, the sintering curve can be divided into three stages: linear expansion during heating, shrinkage during isothermal sintering and shrinkage during cooling. The sharp increase in the diameter of the sample during the initial stage of the sintering process was caused by the thermal expansion phenomenon. As the sintering temperature decreases, this effect becomes less relevant. The exception is the curve for a temperature of $1000{ }^{\circ} \mathrm{C}$. Due to rapid induction heating, the effects related to the $\alpha+\beta \rightarrow \beta$ phase transformation, during which the $\alpha$-hcp crystalline structure transformed into the full 

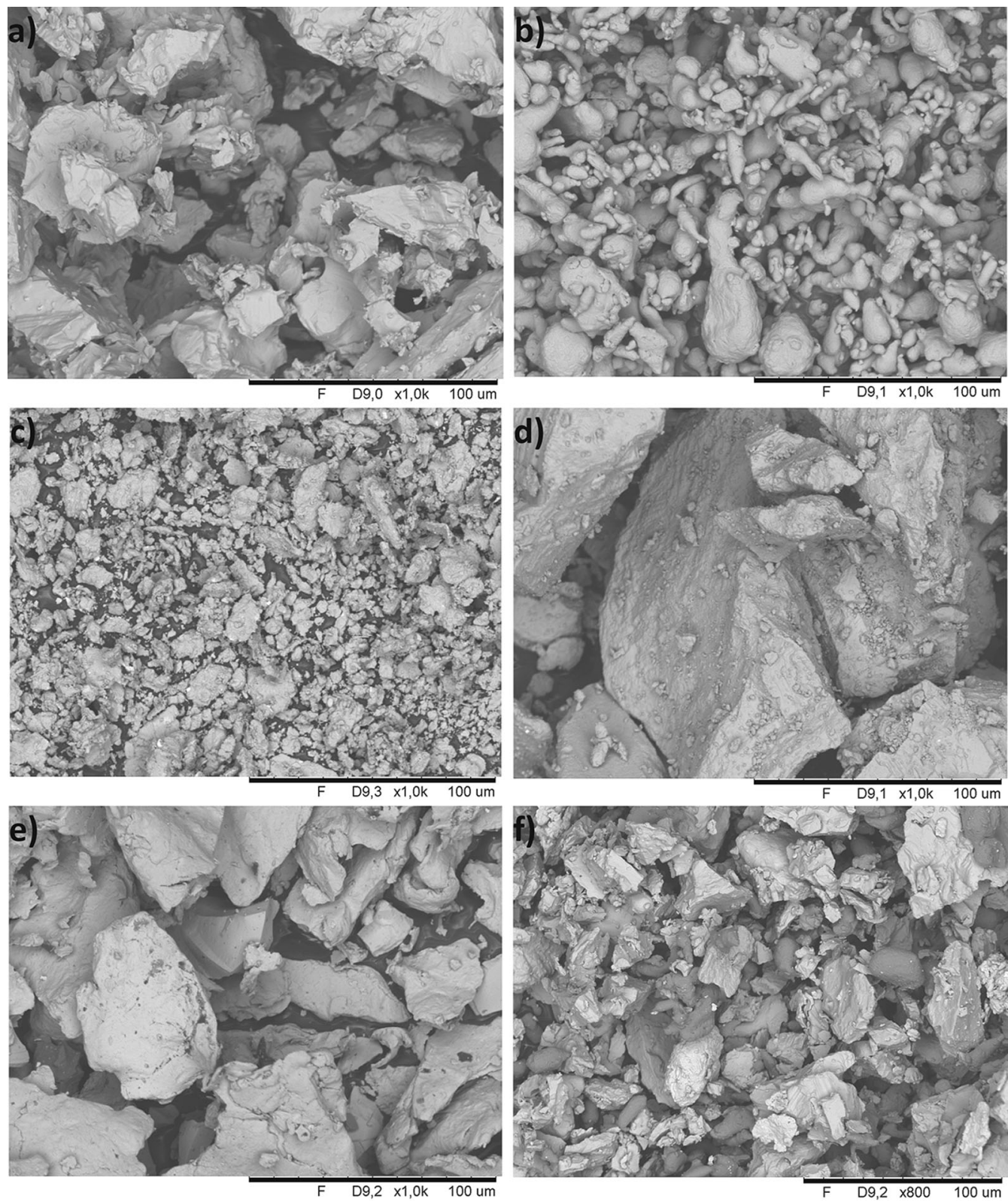

Fig. 1-SEM image of $(a)$ titanium, $(b)$ aluminum, $(c)$ molybdenum, $(d)$ vanadium, $(e)$ chromium elemental powders and $(f)$ Ti-5553 powder mixture.

$\beta$-bcc crystalline structure, were not observed on sintering curves. ${ }^{[29]}$ Rapid shrinkage in the early period of the isothermal sintering process was observed, followed by slowing down until cooling, where once again sharp shrinkage occurred, which is natural for this stage of sintering.

The shrinkage observed on the sintering curves can be divided into two types: first, shrinkage during the entire sintering process, i.e., from the moment when heating starts to the end of cooling. However, considering the size of the sample before heating, and at the end of the process, we also take into account thermal expansion phenomena. Therefore, it will be more meaningful to only consider shrinkage during isothermal treatment, i.e., from the moment when the sample reaches the chosen sintering temperature to the moment when cooling starts. Shrinkage values during isothermal treatment calculated from sintering curves are shown in Figure 3(b). In contrast to the densification studies, no pronounced relationship between the increase of temperature and shrinkage was observed. The best results during isothermal heating were obtained for the temperature of $1100{ }^{\circ} \mathrm{C}$.

\section{Observations of Microstructure}

Microstructure observations of unetched samples using light microscopy (Figure 4) revealed a similar amount of porosity in each sample regardless of the sintering temperature. In particular cases, the samples 


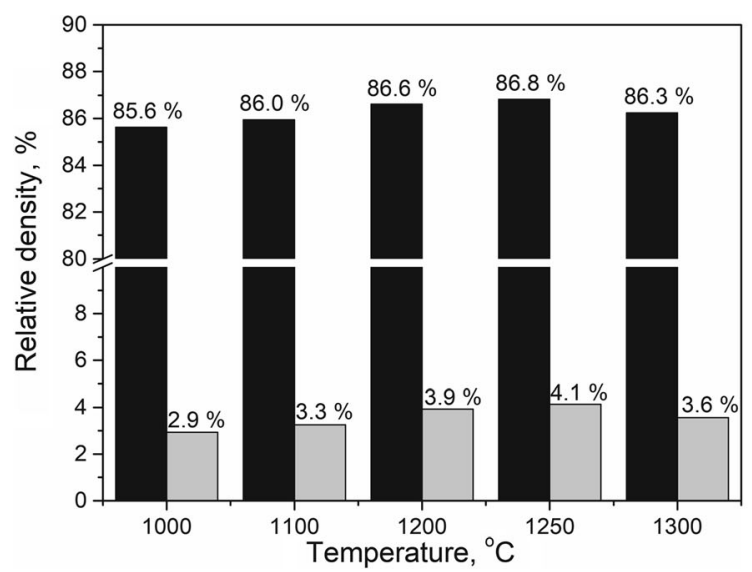

(a)

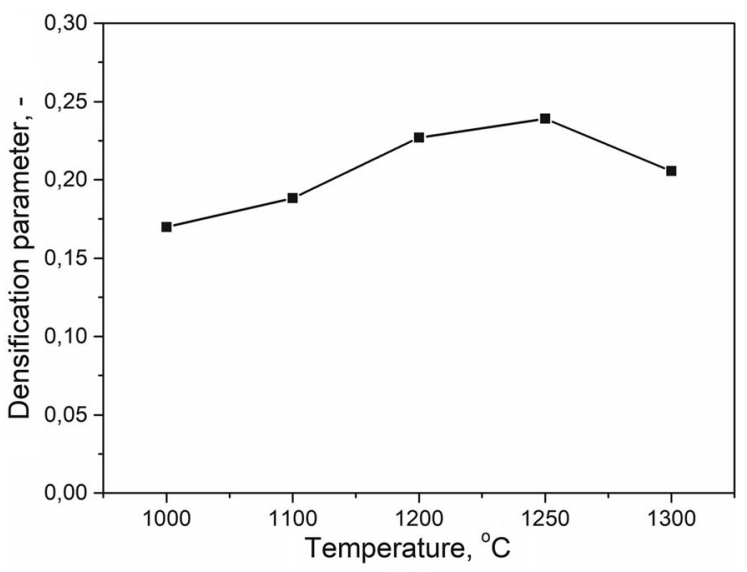

(b)

Fig. 2-Influence of sintering temperature on the (a) relative density (black columns) and density increment of relative density after the sintering process (gray columns) and (b) densification parameter.

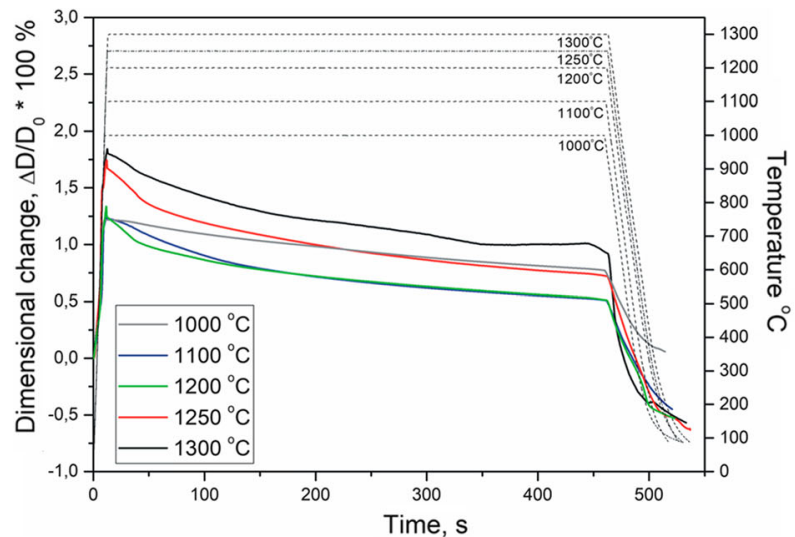

(a)

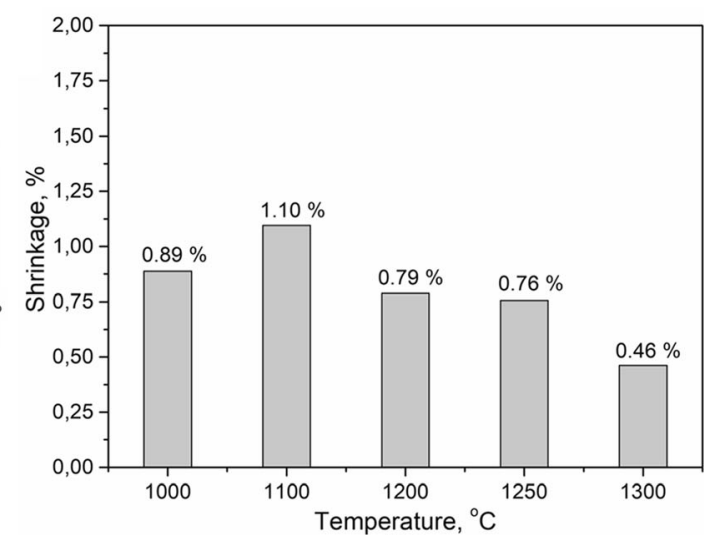

(b)

Fig. 3-(a) Sintering curves for Ti-5553 alloy compact sintered at various temperatures for $450 \mathrm{~s}$ measured in the radial direction and (b) shrinkage during isothermal sintering.

sintered at higher temperatures had a more visible pores (marked by the yellow arrow) than those sintered at a lower temperature. The size of the pores did not exceed $100 \mu \mathrm{m}$. The undissolved particles (marked by red arrows) were still clearly visible in the microstructure of the samples sintered at the temperature of $1000{ }^{\circ} \mathrm{C}$ (Figure 4(a)) and $1100{ }^{\circ} \mathrm{C}$ (Figure 4(b)). Moreover, no evidence of undissolved particles was noticed in the microstructure of the samples sintered at the temperature of $1200^{\circ} \mathrm{C}$ and above (Figure 4(c) through (e)). The average porosity calculated based on the micrographs (Figure 4(f)) confirmed qualitative observations, where similar levels of porosity were noticed. This led to the conclusion that the differences between samples sintered at each sintering temperature were not significant. The lowest porosity was observed in the sample sintered at the temperature of $1100^{\circ} \mathrm{C}$ and the highest in the case of other samples sintered at the temperature of $1000{ }^{\circ} \mathrm{C}$. The average porosity in samples sintered above the temperature of $1200{ }^{\circ} \mathrm{C}$ was very similar.

The etched microstructures of sintered Ti-5553 alloy are presented in Figure 5. In the microstructure of the samples sintered at temperatures of $1000^{\circ} \mathrm{C}$ and $1100{ }^{\circ} \mathrm{C}$ (Figures 5(a) and (b)), the primary powder particles could still be distinguished (blue dashed line). The typical grain structure was not clearly visible; instead, massive undissolved particles were still present. In the microstructure of the samples sintered at temperatures $>$ $1200{ }^{\circ} \mathrm{C}$ (Figures 5(c) through (e)), no significant number of undissolved particles was noticed as well as the separate powder particles with evident unconnected particle boundaries. The porosity occurred in the closed form, spherical pores (Figures 5(c) and (e)) or open form in the pore network (Figure 5(d)). The typical microstructure of $\beta$-titanium alloys after rapid cooling was formed. Coarse $\beta$ phase grains, as well as thin acicular $\alpha$ phase precipitations, were observed.

\section{E. Flow Behavior}

The stress-strain curves for Ti-5553 alloy compacts sintered at different temperatures obtained from the hot compression test were presented in Figure 6(a). All curves were characterized by the initial stress peak 

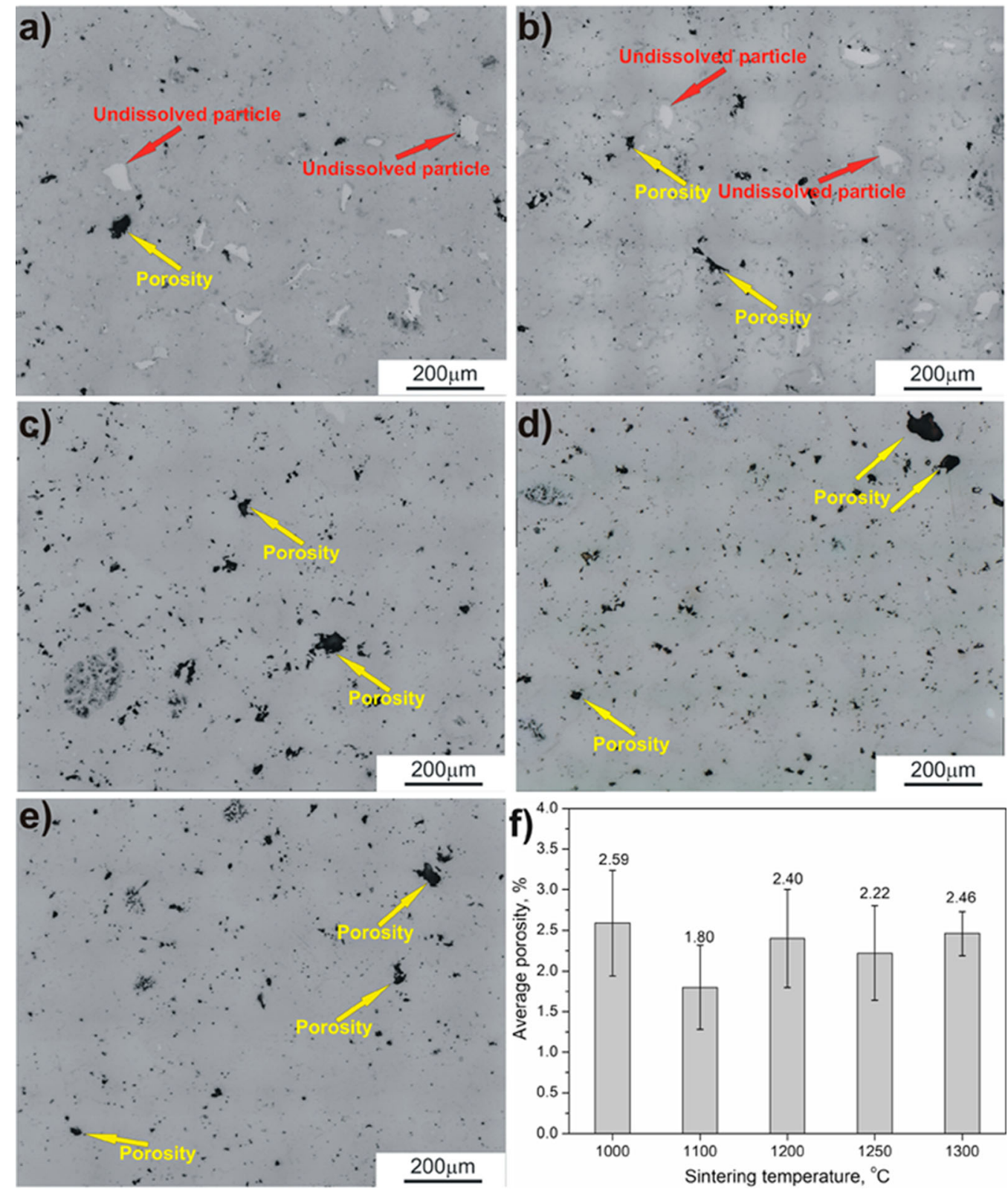

Fig. 4-Microstructures of Ti-5553 alloy sintered at the temperatures of $($ a $) 1000{ }^{\circ} \mathrm{C}$, (b) $1100{ }^{\circ} \mathrm{C},($ c) $) 1200{ }^{\circ} \mathrm{C},($ d $) 1250{ }^{\circ} \mathrm{C}$, (e) $1300{ }^{\circ} \mathrm{C}$ (unetched) and $(f)$ average porosity calculated from the micrographs.

followed by discontinuous yielding. With an increase of the strain, more steady-state flow behavior was noticed. With increasing sintering temperature, the flow stress decreased. There is a significant difference in flow stress between samples sintered below and above the temperature of $1200{ }^{\circ} \mathrm{C}$. Samples sintered below the temperature of $1200{ }^{\circ} \mathrm{C}$ were characterized by higher stress values and sharper stress peaks compared to those, which were sintered at the temperature of $1200{ }^{\circ} \mathrm{C}$ or above. Analyzing the peak stress values and steady-state flow stress (Figure 6(b)), there is a non-linear correlation between hot deformation stress for the samples sintered below and above $1200{ }^{\circ} \mathrm{C}$. Increasing the temperature from $1200{ }^{\circ} \mathrm{C}$ resulted in a gradual decrease in stress. At lower temperatures, the same relationship could be observed for peak stress values, but a slight increase was noticed for steady-state flow stress.

The microstructures of the samples after hot compression tests are presented in Figure 7. Undissolved particles were still present in the microstructures of samples sintered at the temperatures of $1000{ }^{\circ} \mathrm{C}$ and $1100{ }^{\circ} \mathrm{C}$ and deformed in a compression test. It should be noted that some particles were elongated in the material flow direction. Additionally, it was found that in the case of the sample sintered at $1100{ }^{\circ} \mathrm{C}$, the material cracked during the hot compression test (Figure 7(b)). With increasing sintering temperature, the number of pores decreased, no significant undissolved particles could be found, and the microstructure was more homogeneous. Due to the hot deformation 


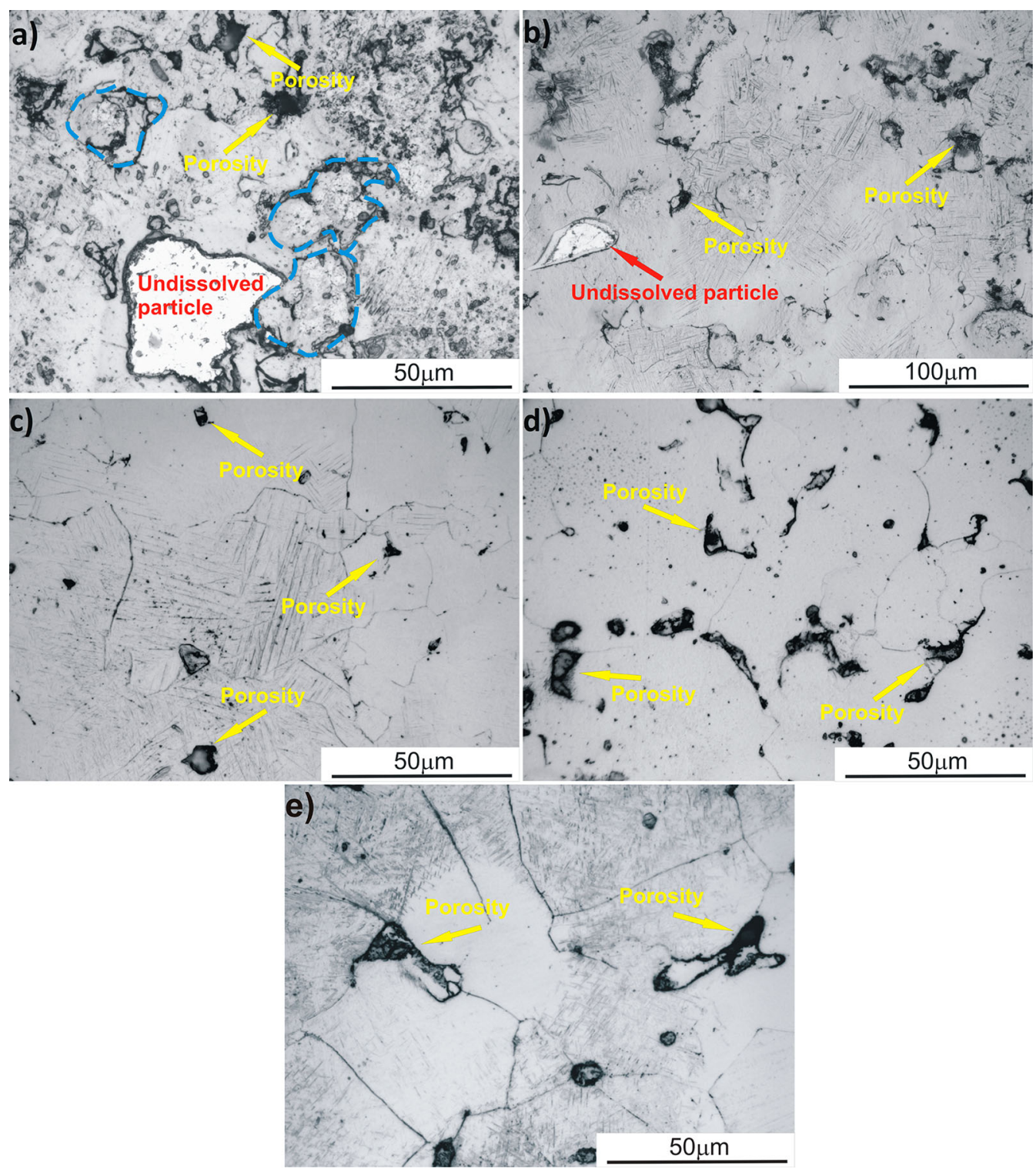

Fig. 5-Microstructures of Ti-5553 alloy sintered at the temperatures of $($ a $) 1000{ }^{\circ} \mathrm{C},\left(\right.$ b) $1100{ }^{\circ} \mathrm{C},(c) 1200{ }^{\circ} \mathrm{C},(d) 1250{ }^{\circ} \mathrm{C}$ and $(e) 1300{ }^{\circ} \mathrm{C}$ (etched). The blue dashed line shows the primary powder particles (Color figure online).

process and the slow air cooling, the microstructure remodeled from the equiaxed, almost fully $\beta$ to fine $\alpha$ grains in the $\beta$ phase matrix. The $\alpha$ grains were arranged in bands, and some of them were elongated in the material flow direction.

\section{F. Hardness Measurements}

Figure 8 shows the hardness measurement results for sintered Ti-5553 alloy compacts with their respective sintering temperatures. The average hardness was measured at the center of the cross sections of each sample. For as-sintered samples, the lowest average hardness was measured for the sintering temperature of $1000{ }^{\circ} \mathrm{C}$ and the highest for the sintering temperature of $1250{ }^{\circ} \mathrm{C}$ (209 and $342 \mathrm{HV}_{1}$, respectively). Due to the hot deformation, followed by air cooling, the average hardness approximately doubled. It was found that the chemical homogenization and the state of the microstructure had a significant impact on the average hardness values. For the samples sintered at lower temperatures, the poor bonding of the powder particles and the presence of the softer and undissolved particles caused low average hardness (sintering temperature of $1000{ }^{\circ} \mathrm{C}$ ) and significant differences in the results (sintering temperature of $1100{ }^{\circ} \mathrm{C}$ ). For higher sintering temperatures, the differences in average hardness were not significant. Relatively low average hardness for the sample sintered at the temperature of $1300{ }^{\circ} \mathrm{C}$ was caused by the presence of coarse $\beta$ grains. The microstructure remodeling and generation of the dislocations during hot deformation were the reason for an increase in hardness. The softer undissolved particles, which were still present after hot compression, similarly to the as-sintered samples, caused a large variance in hardness and the low average value of hardness. For the 


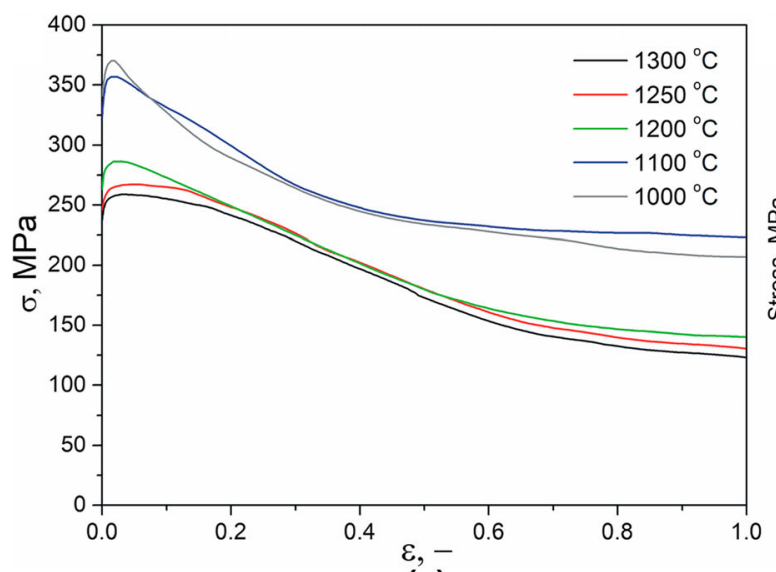

(a)

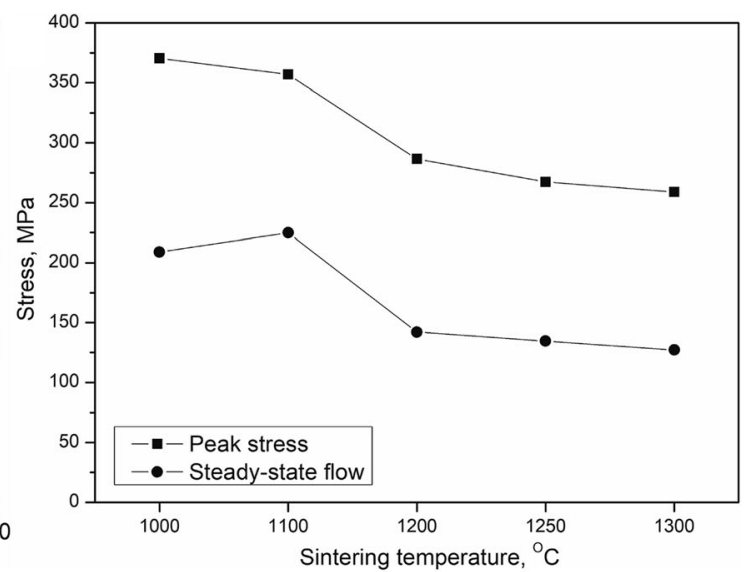

(b)

Fig. 6- (a) The stress-strain curves for Ti-5553 alloy compacts sintered at different temperatures and deformed in compression at the temperature of $1000{ }^{\circ} \mathrm{C}$ and strain rate $1 \mathrm{~s}^{-1} ;(b)$ the value of the peak stress and steady-state flow.

compressed samples sintered at the temperature of 1200 ${ }^{\circ} \mathrm{C}$ and above, the average hardness was similar.

\section{DISCUSSION}

\section{A. Effect of Initial Material and Sintering Conditions on the Densification}

The particle size of the powders used to prepare the powder mixture was in a range of 35 to $150 \mu \mathrm{m}$. As a result of the blending process with WC balls used to intensify milling, some of the particles crashed into a smaller size. Previous research works ${ }^{[30,31]}$ reported that with decreasing particle size, the resulting relative density of the compact increased. However, it should be noted that the mentioned results concerned mixtures containing the same average particle size. Oh et al. ${ }^{[32]}$ studied the influence of using the bimodal powder mixture and revealed that the addition of nano-particles not exceeding 25 pct of the mixture volume increases the relative density. This phenomenon occurs because smaller particles fill in the gaps between irregular micro-particles. Increasing the nano- to microparticle ratio results in the formation of scaffold structures and pore formation. Similar observations were noted in the presented studies. Large particles (up to $150 \mu \mathrm{m}$ ), such as titanium powder particles, vanadium powder particles, and chromium powder particles, constitute the vast majority in the mixture. Smaller particles (up to $35 \mu \mathrm{m}$ ) such as aluminum powder particles and molybdenum powder particles were inserted on the surface of other particles during the blending process and filled the gaps between larger particles during the cold compaction process. Therefore, the density after cold compacting was relatively high, while after the sintering process, the spherical pores were more common than the pore networks.

As a result of the cold compacting process, a high relative density value was achieved. This was influenced by the shape of the die and the small sample size as well as the applied lubrication. Nevertheless, further induction sintering provides similar densification results compared to furnace sintering, ${ }^{[33]}$ but in a significantly shorter time. Raynova et al. ${ }^{[34]}$ studied the impact of the green density on densification during induction sintering. It has been revealed that with increasing green compact density, the increment of the density during sintering decreased significantly. Similar observations can be concluded from this study. The increment of density due to the sintering process was relatively small (up to 4.1 pct for the sintering temperature of $1250{ }^{\circ} \mathrm{C}$ ). Comparing the densification parameter $\psi$ values, the temperature of $1250{ }^{\circ} \mathrm{C}$ should be considered as most beneficial for improving the relative density. Further increasing the sintering temperature does not cause significant effects. Panigrahi et al. ${ }^{[35-37]}$ studied the influence of different volumes of $\mathrm{Ni}$ powder addition on the sintering behavior of titanium powder. The $\mathrm{Ni}$ addition reduced the sintering activation energy significantly compared to the sintering of pure titanium powder and caused an increase of shrinkage (up to about 14 pet for 5 pet $\mathrm{Ni}$ powder addition). During furnace sintering alongside the diffusion process, the reactions between $\mathrm{Ti}$ and $\mathrm{Ni}$ took place, such as the formation of intermetallics and formation of the liquid phase at grain boundaries. Those reactions are highly exothermic, which is beneficial for the shrinkage phenomenon. Considering the above, the complex chemical composition of the powder mixture used in this study, with mostly $\beta$ phase-stabilizing chemical elements, may have a positive impact on the densification. However, in the case of induction sintering, the exposure to the high temperature is much shorter, which results in lower shrinkage (up to $1.1 \mathrm{pct}$ ). Therefore, the influence of the sintering temperature on the chemical and microstructural homogenization requires deeper analysis.

The pore size fraction with respect to the sintering temperature and average pore size is presented in Figure 9(a). Irrespective of the sintering temperature, the most pores were with size from 2 to $7 \mu \mathrm{m}(\sim 76$ to 84 pct). No more than 17 pct of pores with size from 8 to 13 $\mu \mathrm{m}$ were observed. The share of significantly large pores 

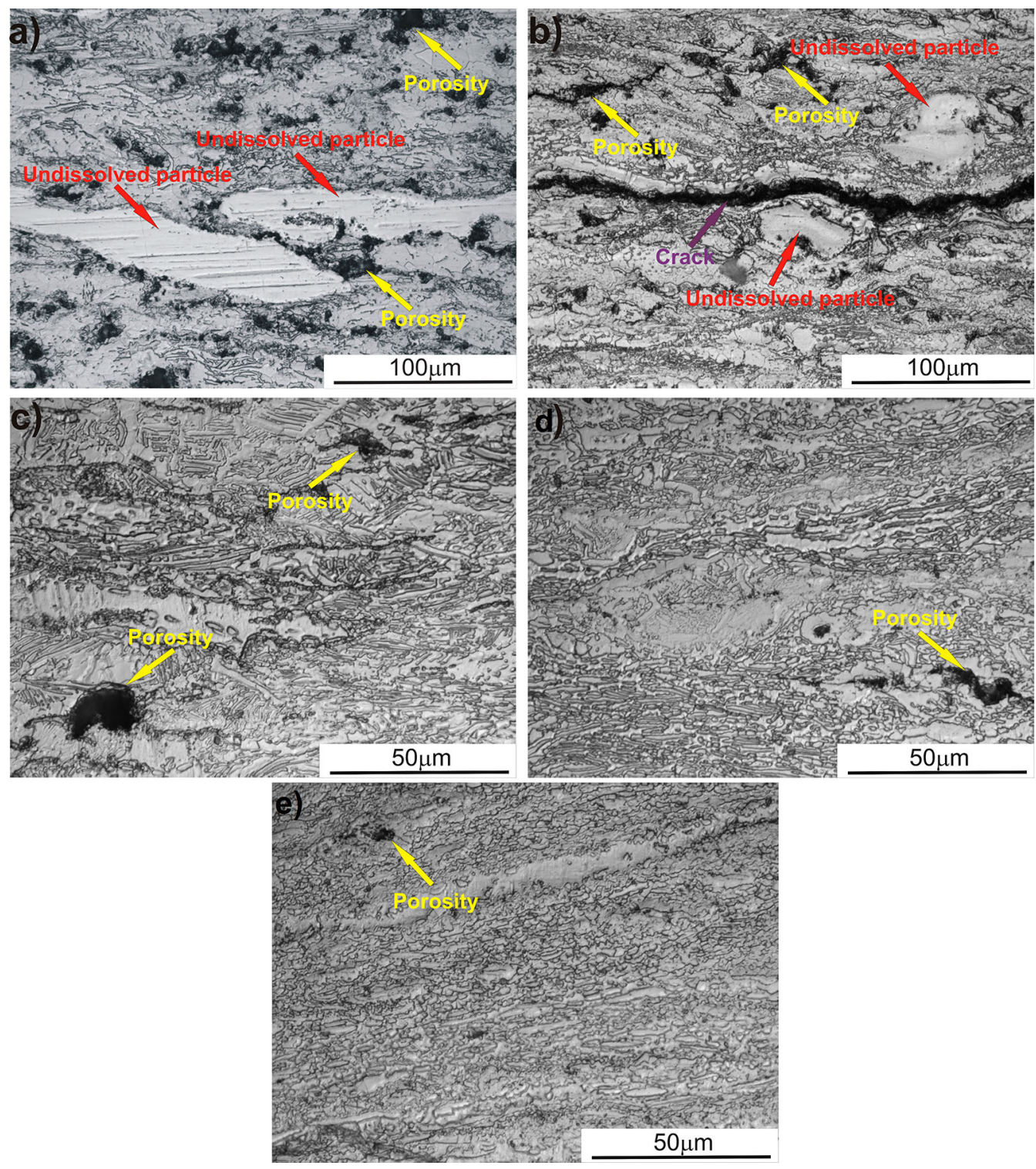

Fig. 7-Microstructures of Ti-5553 alloy compacts sintered at the temperatures of $(a) 1000{ }^{\circ} \mathrm{C},(b) 1100{ }^{\circ} \mathrm{C},(c) 1200{ }^{\circ} \mathrm{C},(d) 1250{ }^{\circ} \mathrm{C}$ and $(e)$ $1300{ }^{\circ} \mathrm{C}$ after hot compression test performed at the temperature of $1000^{\circ} \mathrm{C}$ and strain rate $0.1 \mathrm{~s}^{-1}$ (etched).

with a size of $\geq 50 \mu \mathrm{m}$ was insignificant $(<0.2 \mathrm{pct})$. The average pore size irrespective of the sintering temperature was in the range from 6 to about $7 \mu \mathrm{m}$ (Figure 9(b)). Similar values were previously reported for induction sintering of commercially pure (CP) titanium powder or mixtures of elemental powders based on titanium consolidated in comparable conditions. ${ }^{[1,25,34]}$

\section{B. Microstructural Analysis of As-Sintered Material}

Analyzing the microstructure of the samples sintered at temperatures of $1000^{\circ} \mathrm{C}$ and $1100{ }^{\circ} \mathrm{C}$, the undissolved alloying element particles are still present (Figure 5). Increasing the temperature above $1200{ }^{\circ} \mathrm{C}$ resulted in homogenization of the microstructure and the disappearance of separate alloying element particles. A similar sintering temperature was previously reported for other titanium alloys manufactured by different powder metallurgy methods. ${ }^{[11,38]}$ Ivasishin and Savvakin $^{[39]}$ studied the chemical and microstructural homogenization of Ti-5553 alloy obtained by the BEPM technique and furnace sintering. It was found that sintering at the temperature of $1250{ }^{\circ} \mathrm{C}$ for 2 hour provides full chemical and microstructural homogenization. Further increasing of the sintering time was aimed at increasing the relative density. Compared to furnace sintering, the induction sintering process requires significantly less time to achieve a similar degree of homogenization and properties of sintered materials. This is primarily due to the possibilities of the improvement of the processing parameters resulting from a significant increase in heating rates, sintering temperature and the local increase of temperature resulting from the concentration of electrical current around pores. ${ }^{[40]}$ Better diffusivity during induction sintering results from 
the rapid dissolution of primary grain boundaries and cracking of the oxide layer on the surface of the powder particle. In this study, a similar level of microstructural and chemical homogenization was achieved during induction sintering at the temperature of $1000{ }^{\circ} \mathrm{C}$ for $450 \mathrm{~s}$ as for classic furnace sintering at the same temperature for an hour. ${ }^{[5]}$ Recent studies showed that after induction sintering of titanium alloys, the content of oxygen is lower compared to the vacuum furnace sintering. ${ }^{[41]}$ This has a direct impact on the mechanical properties of the sintered materials. It has been shown that higher oxygen content increases the tensile strength, but at the same time has an unfavorable effect on elongation.

Despite a high relative density of the samples, the primary powder particles still can be distinguished, especially at lower sintering temperatures. The particles

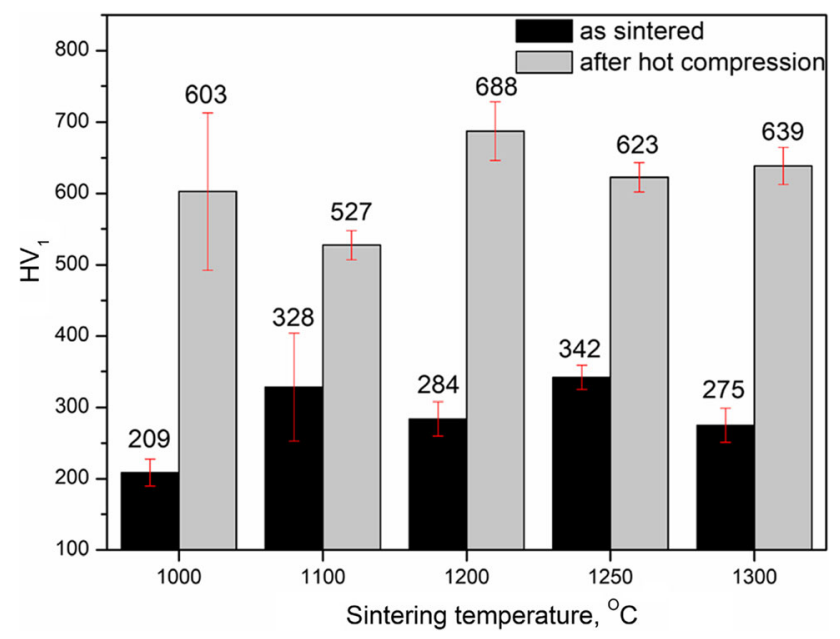

Fig. 8-Influence of the sintering temperature on the hardness of Ti-5553 alloy compacts in as-sintered condition and after hot compression tests. with the most difficult dissolution were identified using the SEM/EDS method. The microstructure of the sample sintered at the temperature of $1000{ }^{\circ} \mathrm{C}$ with indicated points where the EDS measurements were performed is presented in Figure 10. Light gray (point 'a') and white (point 'b') undissolved particles were identified as chromium and molybdenum, respectively. Mo is a chemical element having the highest melting point from all of the mixture ingredients and $\mathrm{Cr}$ has a relatively low diffusion coefficient at this temperature. ${ }^{[42]}$ Nevertheless, the EDS analysis at point ' $a$ ' has shown that some chemical elements such as $\mathrm{Ti}, \mathrm{Al}$ and $\mathrm{V}$ started to diffuse. The dark gray phase (point 'c') contains $\mathrm{Ti}, \mathrm{V}$ with a higher concentration of $\mathrm{Al}$ compared to the light gray phase (point ' $d$ '), which indicates that the dark gray phase consists mostly of $\alpha$ acicular grains and light gray of $\beta$ grains.

With increasing temperature, the observation of the necking formation phenomenon and development of the new grains is possible. The microstructure of the sample sintered at $1100{ }^{\circ} \mathrm{C}$ is presented in Figure 11. The blue dashed line signifies the primary particle boundary, and the purple arrows signify the place where the necking was starting to form. The dominant mass-transfer mechanism during the sintering process was solid-state diffusion. The neck growing between two neighboring particles accelerates the atom transfer between two particles and improves the chemical homogeneity. Before the material starts to diffuse from one particle to another, the oxide layer on the particle surface has to fracture because of the material expansion at high temperatures. The application of induction heating significantly increases the heating rates, which causes rapid thermal expansion, accelerates the necking formation and leads to a reduction of the sintering time. ${ }^{[34]}$ Increasing the sintering temperature also has a beneficial influence on the material diffusion process. It has been previously reported that sintering above the $\beta$-transus temperature enhanced the self-diffusion of the titanium

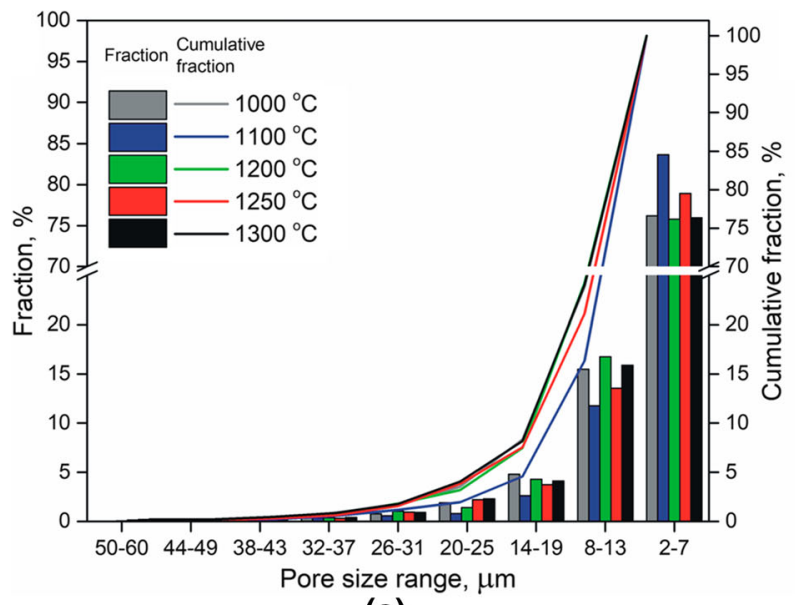

(a)

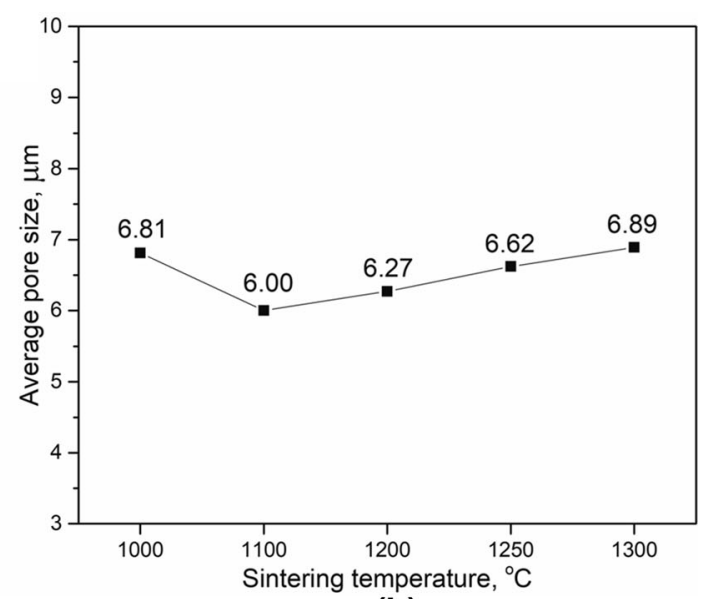

(b)

Fig. 9-Influence of sintering temperature on $(a)$ pore size fraction and $(b)$ average pore size. 

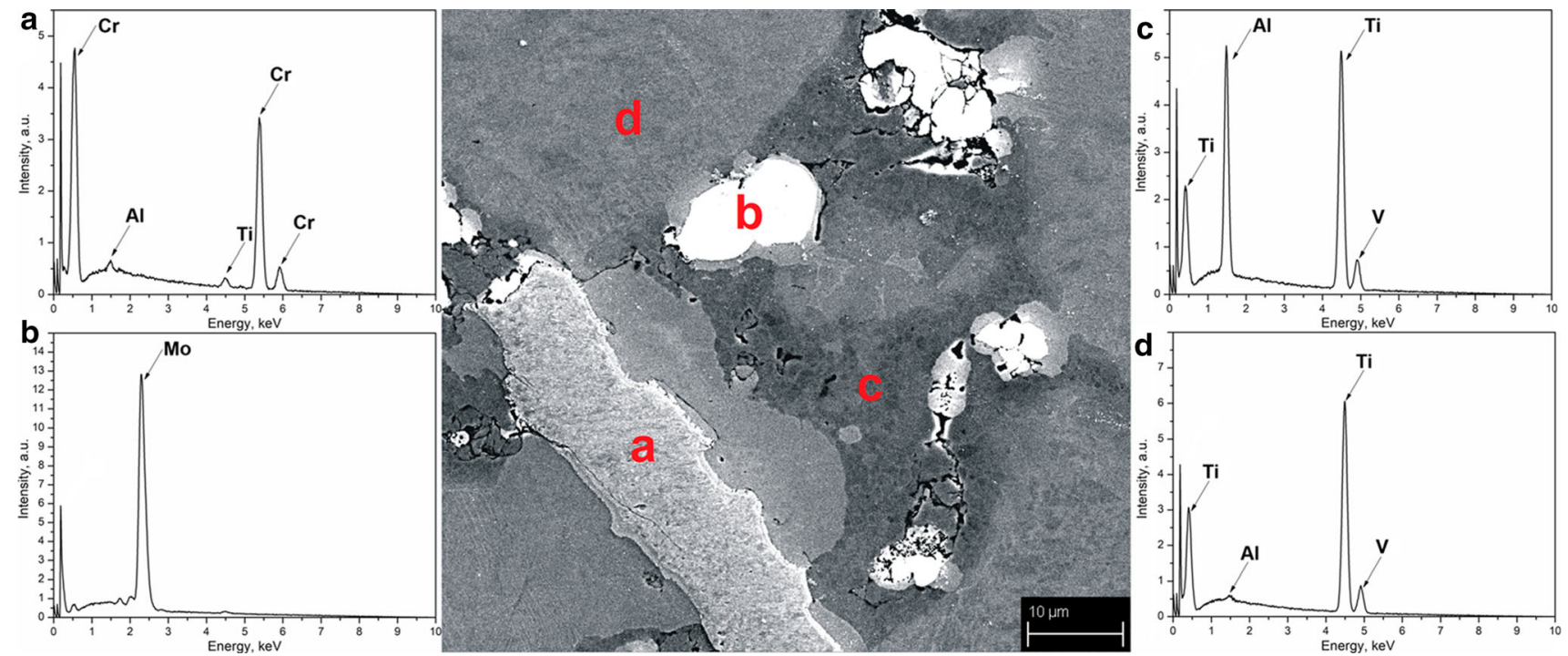

Fig. 10-SEM image of the Ti-5553 alloy sintered at the temperature of $1000{ }^{\circ} \mathrm{C}$ and EDS spectra corresponding to the measurement points. The following points have been identified as: $(a)$ undissolved Cr particle; $(b)$ undissolved Mo particle; $(c) \alpha$ precipitation-rich phase; $(d) \beta$ grains rich phase.

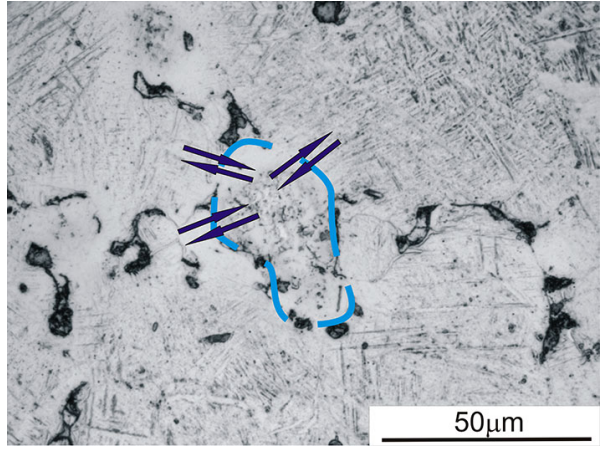

Fig. 11-Microstructures of Ti-5553 alloy sintered at the temperature of $1100{ }^{\circ} \mathrm{C}$. The blue dashed line signifies the primary powder particles. The purple arrows indicate the place where the neck was formed and diffusion occurred.

as well as aluminum, where its diffusion coefficient in $\beta$-Ti increased when increasing the temperature. ${ }^{[6,43]}$

The microstructure of Ti-5553 alloy sintered at a temperature $>1250{ }^{\circ} \mathrm{C}$ consisted of equiaxed $\beta$ grains and thin acicular $\alpha$ phase precipitations. The SEM-EDX elemental maps (Figure 12) showed the differences in the distribution of titanium and other alloying elements. The chemical homogenization was significantly improved at this temperature. This is because alloying elements included in the powder mixture had about ten times better diffusivity in $\beta$-titanium at a temperature of $1250{ }^{\circ} \mathrm{C}$ than at $1020{ }^{\circ} \mathrm{C} \cdot{ }^{[5]}$ The concentration of $\mathrm{Ti}$ and $\mathrm{Al}$ was higher around the $\alpha$ phase precipitations, while the Mo and $\mathrm{Cr}$ around the full- $\beta$ phase. The distribution of $\mathrm{V}$ was uniform regardless of the phase field. Even though the primary alloying powder particles cannot be distinguished after sintering at the temperature of 1250 ${ }^{\circ} \mathrm{C}$, the stabilization effect of $\mathrm{Al}$ (stabilizing $\alpha$ phase) and Mo, $\mathrm{V}$ and $\mathrm{Cr}$ (stabilizing $\beta$ phase) may disrupt the redistribution of alloying elements by the creation of the phase barriers. Nevertheless, previous studies ${ }^{[5,39]}$ revealed that the application of pure elemental powders results in more uniform distributions of alloying elements than the master alloy powders with a complex chemical composition. When the alloying elements are introduced to the material as one powder, the diffusion of $\beta$-stabilizing elements is impeded by the saturation of the aluminum in this area, while at higher temperatures the effect is the opposite.

\section{Flow Characteristics and the Effect of Deformation on the Microstructure and Material Properties}

Various sintering temperatures influenced the flow behavior of the Ti-5553 compacts at constant hot compression conditions. The discontinuous yielding phenomenon, which can be described as an initial flow stress increase followed by a drop in stress value, was previously observed for many types of titanium alloys, also for those produced by powder metallurgy techniques. It is probably associated with the rapid generation of new dislocations on grain boundaries. ${ }^{[22,44,45]}$ With an increase of strain, the flow stress decreased and became more steady state, which indicated that softening effects [dynamic recrystallization (DRX), dynamic recovery (DRV)] may occur and compensate the work hardening. Significantly, higher flow stress values for the samples that were sintered below $1200{ }^{\circ} \mathrm{C}$ were caused by the presence of the undissolved particles that blocked the movement of the dislocations during the hot compression process. This effect can be compared with the hot deformation of titanium alloy matrix composites, where the reinforcement particles interrupt the movement of dislocations. As a result, the peak stress value for the composite may be higher compared to the unreinforced titanium alloy matrix. ${ }^{[46,47]}$ Increasing the sintering temperature above $1200{ }^{\circ} \mathrm{C}$ results in a significant decrease in flow stress (about $100 \mathrm{MPa}$ ). 


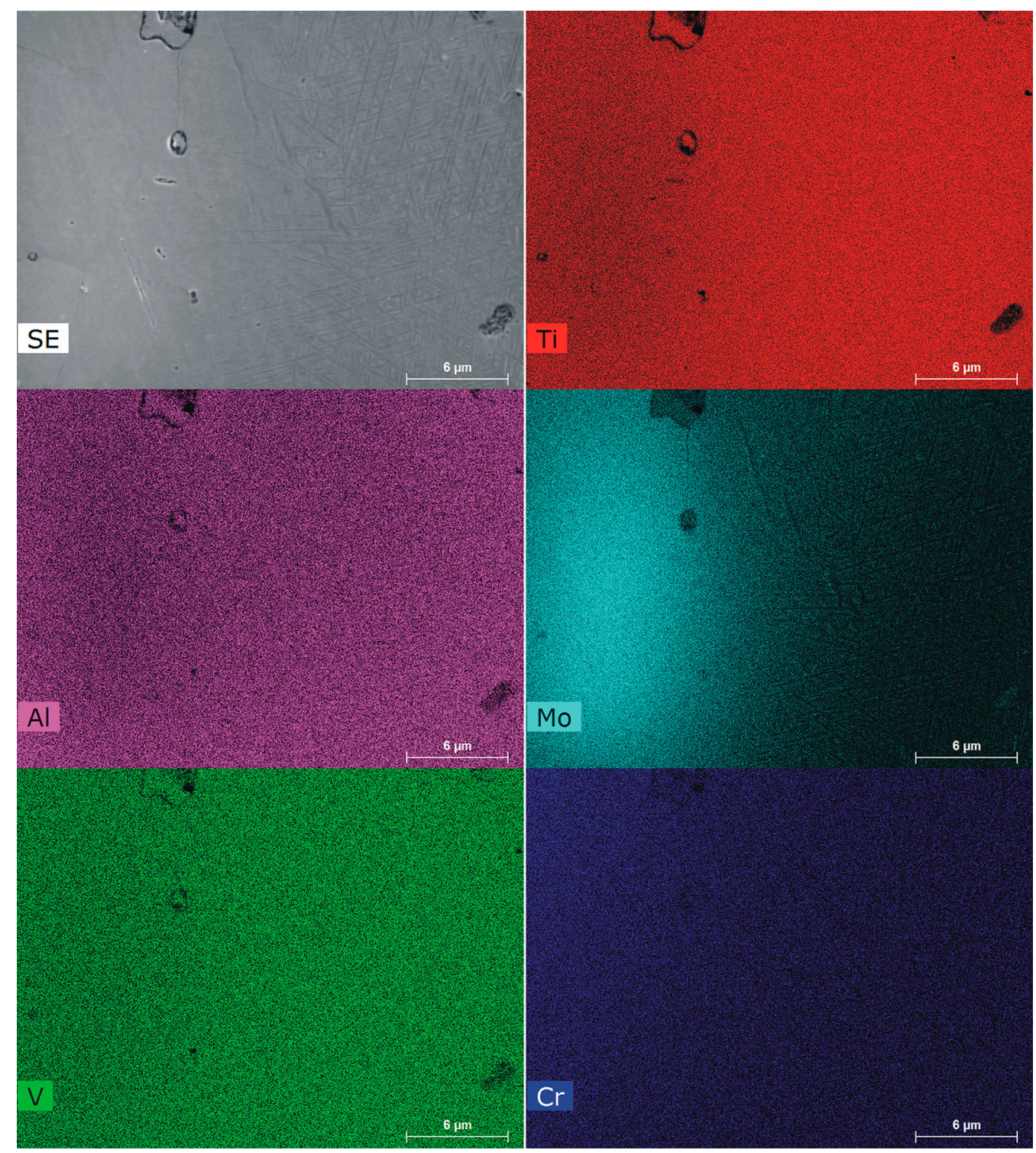

Fig. 12-SEM-SE image and corresponding Ti, Al, Mo, V and $\mathrm{Cr}$ elemental distribution maps for Ti-5553 alloy induction sintered at the temperature of $1250{ }^{\circ} \mathrm{C}$.

Nevertheless, the obtained flow curves are characterized by a sharper and higher flow stress peak at the beginning of the deformation. Compared to the Ti-5553 alloy manufactured by the conventional casting route, the steady-state flow stress value is about $50 \mathrm{MPa}$ higher. ${ }^{[22]}$ This effect may be the consequence of the powder mixture preparation and the application of WC balls. Powder particles were intensively broken up during the mixing process and were exposed to oxygen contamination. Titanium alloys exhibit sensitivity to the changing oxygen content. ${ }^{[48]}$ The increased oxygen level inhibited the $\beta$-phase stabilization effect of other alloying elements such as vanadium, molybdenum or chromium and increased the $\beta$-transus temperature. The higher volume fraction of $\alpha$ phase in the material during hot compression increased the flow stress, because the $\alpha$ phase with a hexagonal close-packed (hcp) lattice structure has worse deformability than $\beta$ phase with a body-centered cubic (bcc) lattice structure.

Some of the undissolved powder particles remained in the microstructure after sintering at the temperatures of $1000{ }^{\circ} \mathrm{C}$ and $1100{ }^{\circ} \mathrm{C}$ (Figures 7(a) and (b)) and were not deformed during hot deformation. Those particles impede the flow of the material, which resulted not only in increasing the flow stress but also suppressed closing up of the pores. The microstructure after the deformation of samples sintered at lower temperatures is uneven. There are regions richer in lamellar $\alpha$ grains and others composed of fine equiaxed $\beta$ grains. This is the result of the inhomogeneity in the chemical composition of the material sintered at too low temperature. Increasing the sintering temperature above $1200{ }^{\circ} \mathrm{C}$ caused the uniform precipitations of fine $\alpha$ gains on the primary $\beta$ grain boundaries after hot compression and air-cooling. 

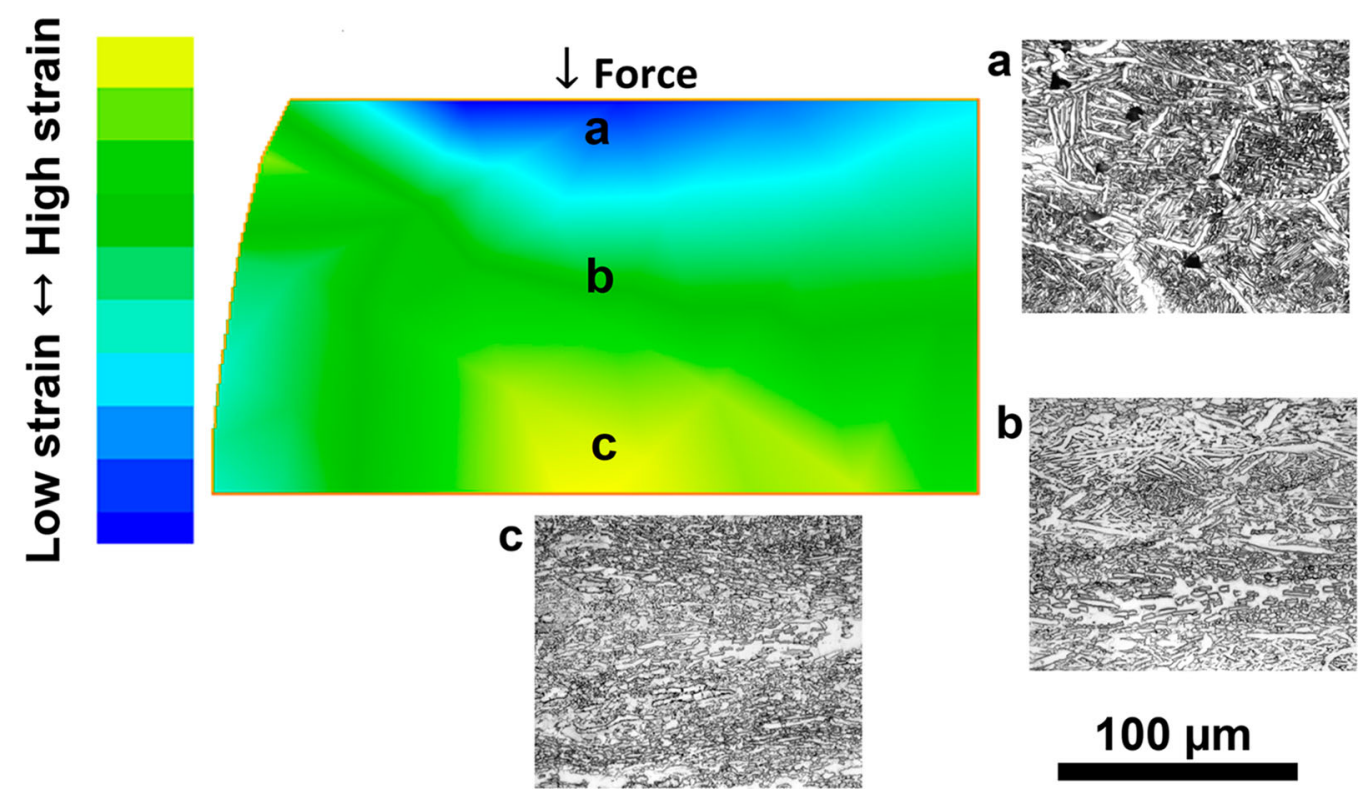

Fig. 13-Schematic representation of the microstructure changes with the increasing strain $[(a)$ low strain, $(b)$ medium strain, $(c)$ high strain $)]$ in the cross section of the hot compressed Ti-5553 alloy sample previously sintered at $1250{ }^{\circ} \mathrm{C}$.

The comparison of the microstructure changes in hot deformed samples sintered at $1250{ }^{\circ} \mathrm{C}$ is shown in Figure 13. As mentioned previously, above the sintering temperature of $1200{ }^{\circ} \mathrm{C}$, the microstructure after hot compression is well homogenized, with no significant undissolved particles that disturb the flow of the material. During axial compression of the cylindrical sample of any solid metallic material, the friction between the flat compression plates and the sample causes the inhomogeneous deformation called "barreling". ${ }^{49]}$ This phenomenon leads to the varied strain values on the cross section of the compressed sample, which results in this case in a different morphology and arrangement of the $\alpha$ phase. Close to the sample contact surface with the plate (area a), where the flow of the material was blocked by the friction force and the strain value is low, the unclosed pores were still visible. The microstructure consists of coarse lamellar $\alpha$ grains located on primary $\beta$ grain boundaries and the colonies of $\alpha$ plates stacked within those boundaries. Such evolution of the microstructure is typical for titanium alloys after being recrystallized from the temperature above the $\beta$-transus. ${ }^{[33,50]}$ With increasing strain value (area b), the pores start to close. The $\alpha$ lamellar grains that contour the primary $\beta$ grain boundaries begin to flatten to the material flow direction and the $\alpha$ plates start to defragment. At the highest strain (area c), the $\alpha$ plates break up to fine, spheroidal equiaxed grains. The primary $\beta$ grain boundaries cannot be distinguished, and the microstructure is oriented to the material flow direction. The observed microstructure evolution was similar to the PM $\beta$ titanium alloy manufactured under different approaches as well as $\alpha+\beta$ titanium alloys hot deformed in a similar process and conditions. ${ }^{[51,52]}$ The type of formed microstructure influenced the mechanical properties of the material and caused some heterogeneity on the cross section of the sample. The hardness measurements performed at areas $\mathrm{a}, \mathrm{b}$ and $\mathrm{c}$ indicated in Figure 13 revealed the gradual increase of the hardness with increasing strain value and hence the fragmentation of the microstructure $\left(459 \mathrm{HV}_{1}, 546 \mathrm{HV}_{1}\right.$, and $623 \mathrm{HV}_{1}$, respectively).

Additionally, the microstructure, remodeled during the hot deformation, may affect the other mechanical properties of the processed material. The cooling from the temperature above $\beta$-transus affected the type of the obtained microstructure, which consisted of fine and fragmented lamellar $\alpha$ grains on the $\beta$ phase matrix. No globular $\alpha$ grains were visible. This type of structure determines the high strength and good fracture toughness of the material but also is responsible for low ductility. ${ }^{[23]}$ Several studies investigated the influence of the morphology and the location of the $\alpha$ phase on the mechanical properties of Ti-5553 alloy obtained by the conventional casting route $^{[53,54]}$ and powder metallurgy. ${ }^{[55,56]}$ Irrespective of the manufacturing method, the microstructure consists of the lamellar $\alpha$ phase, resulting in a significant increase of the tensile strength compared to the initial full $\beta$ microstructure and passable elongation, which is furthermore possible to improve by adequate heat treatment.

\section{CONCLUSIONS}

The sintering behavior of the Ti-5553 alloy obtained by the blended elemental powder metallurgy method and induction sintering process at different temperatures was investigated. The level of the consolidation, shrinkage during sintering and their influence on the material properties were studied. The chemical homogenization as well as microstructure and its evolution during hot processing was analyzed and discussed. 
The main conclusion of this study can be summarized as follows:

1. The density of the cold-compacted material was relatively high (about 83 pct) and the sintering process slightly improved the level of density. The increase of the sintering temperature caused the gradual increment of relative density in relation to the cold-compacted sample. Regardless of the temperature, the average pore share and size were similar. The average pore size did not exceed $7 \mu \mathrm{m}$.

2. The neck formation initiating the material diffusion between powder particles has been observed at the temperature of $1100{ }^{\circ} \mathrm{C}$. Increasing the sintering temperature to $1200{ }^{\circ} \mathrm{C}$ proved to be critical for the chemical and microstructural homogenization of the sintered material. The dissolution of alloying elements was significantly improved above this temperature and the microstructure has become more uniform.

3. Appropriate selection of sintering parameters of the compacts manufactured from a mixture of blended elemental powders allows obtaining high-density material that can be successfully hot deformed. The flow behavior of the investigated material revealed that the dissolution of the alloying particles was crucial for decreasing the flow stress value. Increasing the sintering temperature above $1200{ }^{\circ} \mathrm{C}$ results in significant flow stress reduction. Microstructure analysis of hot deformed samples revealed that the thermomechanical processing of induction sintered $\beta$ titanium alloy induced the microstructural development and contributed to the significant improvement of the mechanical properties.

\section{ACKNOWLEDGMENTS}

The financial support of the Polish Ministry of Science and Higher Education is gratefully acknowledged (AGH-UST Statutory Research Project No. 16.16.110.663). Part of the study was performed using the infrastructure at Institut für Metallformung, TU Bergakademie Freiberg, and the International Centre of Electron Microscopy for Materials Science (ICEM), AGH-UST.

\section{CONFLICT OF INTEREST}

The authors declare that they have no conflict of interest.

\section{OPEN ACCESS}

This article is licensed under a Creative Commons Attribution 4.0 International License, which permits use, sharing, adaptation, distribution and reproduction in any medium or format, as long as you give appropriate credit to the original author(s) and the source, provide a link to the Creative Commons licence, and indicate if changes were made. The images or other third party material in this article are included in the article's Creative Commons licence, unless indicated otherwise in a credit line to the material. If material is not included in the article's Creative Commons licence and your intended use is not permitted by statutory regulation or exceeds the permitted use, you will need to obtain permission directly from the copyright holder. To view a copy of this licence, visit http://creativecommons.org/licenses/by/4.0/.

\section{REFERENCES}

1. R.A. Antunes, C.A.F. Salvador, and M.C.L. de Oliveira: Mater. Res., 2018, https://doi.org/10.1590/1980-5373-mr-2017-0979.

2. F.H. Froes, H. Friedrich, J. Kiese, and D. Bergoint: JOM, 2004, vol. 56, pp. 40-44.

3. L.C. Campanelli, P.S.C.P. da Silva, and C. Bolfarini: Mater. Sci. Eng. A, 2016, vol. 658, pp. 203-09.

4. N.S. Weston and M. Jackson: J. Mater. Process. Technol., 2017, vol. 243 , pp. $335-46$.

5. A. Carman, L.C. Zhang, O.M. Ivasishin, D.G. Savvakin, M.V. Matviychuk, and E.V. Pereloma: Mater. Sci. Eng. A, 2011, vol. 528, pp. 1686-93.

6. Y.F. Yang, S.D. Luo, G.B. Schaffer, and M. Qian: Mater. Sci. Eng. A, 2011, vol. 528, pp. 6719-26.

7. R. Naseri, D.R.G. Mitchell, D.G. Savvakin, M.J.B. Nancarrow, T. Furuhara, A.A. Saleh, A.A. Gazder, and E.V. Pereloma: Mater. Sci. Eng. A, 2019, vol. 747, pp. 232-43.

8. S. Grasso, Y. Sakka, and G. Maizza: Sci. Technol. Adv. Mater., 2009, vol. 10, p. 053001.

9. O. Guillon, J. Gonzalez-Julian, B. Dargatz, T. Kessel, G. Schierning, J. Räthel, and M. Herrmann: Adv. Eng. Mater., 2014, vol. 16, pp. 830-49

10. J.L. Xu, S.C. Tao, L.Z. Bao, J.M. Luo, and Y.F. Zheng: Mater. Sci. Eng. C, 2019, vol. 97, pp. 156-65.

11. M.T. Jia, B. Gabbitas, and L. Bolzoni: J. Mater. Process. Technol., 2018, vol. 255, pp. 611-20.

12. F. Raether and P. Schulze Horn: J. Eur. Ceram. Soc., 2009, vol. 29 , pp. 2225-34.

13. R. Grupp, M. Nöthe, B. Kieback, and J. Banhart: Nat. Commun., 2011, vol. 2, p. 298.

14. S.J. Kang: Sintering, Elsevier, Amsterdam, 2005.

15. S.S. Dheda and F.A. Mohamed: Mater. Sci. Eng. A, 2011, vol. 528 , pp. $8179-86$

16. O. Lypchanskyi, T. Śleboda, M. Wojtaszek, K. Muszka, A. Łukaszek-Sołek, R. Stanik, and M. Gude: Int. J. Mater. Form., 2019, https://doi.org/10.1007/s12289-019-01533-z.

17. M. Wojtaszek, G. Korpała, T. Śleboda, K. Zyguła, and U. Prahl: Metall. Mater. Trans. A, 2020, vol. 51A, pp. 5790-5805.

18. Y.C. Wang and T.G. Langdon: J. Mater. Sci., 2013, vol. 48, pp. 4646-52.

19. L. Bolzoni, S. Raynova, and F. Yang: J. Alloys Compd., 2020, vol. 838 , p. 155559.

20. B. Callegari, J.P. Oliveira, R.S. Coelho, P.P. Brito, N. Schell, F.A. Soldera, F. Mücklich, M.I. Sadik, J.L. García, and H.C. Pinto: Mater. Charact., 2020, vol. 162, p. 110180.

21. K. Zyguła, M. Wojtaszek, O. Lypchanskyi, T. Śleboda, G. Korpała, and U. Prahl: Metall. Mater. Trans. A., 2019, vol. 50A, pp. 5314-23.

22. Q. Zhao, F. Yang, R. Torrens, and L. Bolzoni: Mater. Des., 2019, vol. 169 , p. 107682.

23. L. Kang and C. Yang: Adv. Eng. Mater., 2019, vol. 21, p. 1801359.

24. J.G. Kaufman: Titanium Alloy Database - Knovel, http://app1knovel-1com-1000014rj00eb.wbg2.bg.agh.edu.pl/web/toc.v/cid:k pTAD00001/viewerType:toc//root_slug:titanium-alloy-database/u rl_slug:table-9b-typical-physical?b-q = material_or_substance_na me $\% 3$ Ati- $5553 \&$ b-group-by $=$ true\&b-dsQuery $=\% 3$ Fmn $\% 3 \bar{D}$ ti- 5 553\&b-. Accessed 8 December 2020. 
25. M. Jia and B. Gabbitas: Metall. Mater. Trans. A, 2015, vol. 46A, pp. 4716-29.

26. P. Sun, Z.Z. Fang, Y. Zhang, and Y. Xia: Jom, 2017, vol. 69, pp. $1853-60$.

27. J. Zhang, D. Gu, Y. Yang, H. Zhang, H. Chen, D. Dai, and K. Lin: Engineering, 2019, vol. 5, pp. 2850-57.

28. S. Patra, A. Gouthama, and K. Mondal: Prog. Nat. Sci. Mater. Int., 2014, vol. 24, pp. 608-22.

29. Y.W. Marsumi and A.W. Pramono: Adv. Mater. Res., 2014, vol. 900 , pp. 53-63.

30. I.M. Robertson and G.B. Schaffer: Metall. Mater. Trans. A, 2009, vol. 40A, pp. 1968-79.

31. D.Y. Park, S.W. Lee, S.J. Park, Y.-S. Kwon, and I. Otsuka: Metall. Mater. Trans. A, 2013, vol. 44A, pp. 1508-18.

32. J.W. Oh, Y. Seong, D.S. Shin, and S.J. Park: Powder Technol., 2019, vol. 352, pp. 42-52.

33. K. Zyguła and M. Wojtaszek: Arch. Metall. Mater., 2020, vol. 65, pp. 287-93.

34. S. Raynova, Y. Collas, F. Yang, and L. Bolzoni: Metall. Mater. Trans. A, 2019, vol. 50A, pp. 4732-42.

35. B.B. Panigrahi and M.M. Godkhindi: Intermetallics, 2006, vol. 14 pp. $130-5$.

36. B.B. Panigrahi: Mater. Lett., 2007, vol. 61, pp. 152-55.

37. B.B. Panigrahi, M.M. Godkhindi, K. Das, P.G. Mukunda, and P. Ramakrishnan: Mater. Sci. Eng. A, 2005, vol. 396, pp. 255-62.

38. Y. Liu, L.F. Chen, H.P. Tang, C.T. Liu, B. Liu, and B.Y. Huang: Mater. Sci. Eng. A, 2006, vol. 418, pp. 25-35.

39. O.M. Ivasishin and D.G. Savvakin: Key Eng. Mater., 2010, vol. 436, pp. 113-21.

40. W. Hermel, G. Leitner, and R. Krumphold: Powder Metall., 1980, vol. 23, pp. 130-35.

41. S. Raynova, F. Yang, and L. Bolzoni: Mater. Sci. Eng. A, 2021, vol. 799, p. 140157.
42. S.-Y. Lee, Y. Iijima, and K. Hirano: Mater. Trans. JIM, 1991, vol. 32 , pp. $451-56$

43. S.-Y. Lee, O. Taguchi, and Y. Iijima: Mater. Trans., 2010, vol. 51, pp. 1809-13.

44. I. Philippart and H.J. Rack: Mater. Sci. Eng. A, 1998, vol. 243, pp. 196-200.

45. W. Chuan and H. Liang: Vacuum, 2018, vol. 156, pp. 384-401.

46. X. Wang, L. Wang, L.S. Luo, H. Yan, X.Z. Li, R.R. Chen, Y.Q. Su, J.J. Guo, and H.Z. Fu: Mater. Des., 2017, vol. 121, pp. $335-44$.

47. S.L. Semiatin and T.R. Bieler: Acta mater, 2001, vol. 49, pp. $3565-73$

48. Y.V.R.K. Prasad and T. Seshacharyulu: Mater. Sci. Eng. A, 1998, vol. 243 , pp. $82-88$.

49. R. Narayanasamy and K.S. Pandey: J. Mater. Process. Technol., 2000 , vol. 100 , pp. $87-94$.

50. S.L. Semiatin: Metall. Mater. Trans. A, 2020, vol. 51A, pp. 2593-2625.

51. E. Calvert, B. Wynne, N. Weston, A. Tudball, and M. Jackson: $J$. Mater. Process. Technol., 2018, vol. 254, pp. 158-70.

52. S.L. Semiatin, V. Seetharaman, and I. Weiss: Mater. Sci. Eng. A, 1999, vol. 263, pp. 257-71.

53. M. Sen, S. Suman, T. Banerjee, A. Bhattacharjee, and S.K. Kar: Mater. Sci. Eng. A, 2019, vol. 753, pp. 156-67.

54. Y.C. Lin, L.-H. Wang, Q. Wu, Y.-W. Xiao, H. Cheng, and X.-Y. Zhang: Mater. Res. Express, 2019, vol. 6, p. 1165h2.

55. M. Ahmed, D.G. Savvakin, O.M. Ivasishin, and E.V. Pereloma: $J$. Alloys Compd., 2017, vol. 714, pp. 610-18.

56. F. Yang, B. Gabbitas, M. Dore, A. Ogereau, S. Raynova, and L. Bolzoni: Mater. Chem. Phys., 2018, vol. 211, pp. 406-13.

Publisher's Note Springer Nature remains neutral with regard to jurisdictional claims in published maps and institutional affiliations. 